\title{
The role of green spaces in increasing social interactions in neighborhoods with periodic markets
}

\author{
Farshid Aram ${ }^{\mathrm{a}}$, Ebrahim Solgi ${ }^{\mathrm{b}, *}$, Gordon Holden ${ }^{\mathrm{b}}$ \\ ${ }^{a}$ Department of Urban and Regional Planning, Polytechnic University of Madrid-UPM, Madrid, Spain \\ ${ }^{\mathrm{b}}$ School of Engineering and Built Environment, Griffith University, Australia
}

\section{A R T I C L E I N F O}

\section{Keywords:}

Green space

Social interactions

Attendance

Periodic markets

Neighborhoods

\begin{abstract}
A B S T R A C T
In this research, the effects of green spaces on the extent of residents' socialization behavior as well as the actual presence of people in neighborhood open spaces where daily markets are held, were investigated. The statistical population of this research included residents in six neighborhoods in Hamadan City where daily markets are held. More specifically, social participation in three neighborhoods where the venue of daily markets enjoys green space was compared with three corresponding neighborhoods, where the venue of daily markets lacked green space. The results of the research indicated that in neighborhoods where periodic markets are held in venues with green space, the extent of visits to the market and social behavior, specifically, acquaintance of neighbors with each other, sense of belonging, and the level of cooperation, were greater than that of neighborhoods with no green space. Moreover, effective indices that influence the quality of green spaces were also obtained. These indices, in order of significance, are 1 . The aesthetic allure of urban furniture; 2. Suitable vegetation; 3. Sufficiency of urban furniture and; 4. Suitable flooring.
\end{abstract}

\section{Introduction}

People attend public spaces to meet a requirement. Some of these requirements, such as attendance for shopping are essential and are influenced by space functionality. Others are contingent upon the quality of the environment; that is, given the quality and facilities of the space, the requirements may or may not be met (Gehl, 2013; Ward Thompson, 2013). Carr, Francis, Rivlin, and Stone (1992), also conjectured about cultural forces that form public life and determine the presence of individuals in public places. The first is the social force that occurs in multipurpose public places further to manifold social life-focused activities. The second force is associated with meeting the basic needs of the society, setting the stage for public life and collaborations to satisfy needs. The emergence of markets to sell products and goods in a space is an example of a manifestation of this aim.

Periodic markets are a type of public space in cities where people are extensively and continuously present and different ethnic and age groups interact. Periodic markets have long antiquity and are a type of market that both provide goods for rural people and a place for exchanging rural goods with cities. Indeed, they are places for the activity of various individuals who are engaged in the market with different motives, including economic, social and cultural dimensions (Afsrkshmyry, 1993). Periodic markets are usually held on both sides of a route, in a space used by commuters or even inside a square. These markets lack an architectural space, although in some cases, they are traditionally held in open or shaded spaces utilizing light and inexpensive materials so that goods are protected against sunlight or rainfall. (Soltanzadeh, 1392).

Socially and economically, attendance and social activities of individuals in periodic markets are different in terms of their scale of organization and population of sellers and customers in comparison with other markets. They also differ in terms of the type of activity, in that they have a smaller and local scale and the relationships are warmer and closer (Sommer, Herrick, \& Sommer, 1981). Periodic markets are a socioeconomic venue for numerous villagers and city dwellers. In these markets, both men and women participate in trade, and in some regions where industrial products are important, most often representative of the industry themselves (Khosravi, 1979). Many studies have been conducted on the economic and social role of periodic markets (Ehinmowo \& Ibitoye, 2010; John \& Chikagbum, 2015; Smith, 1979). Social sector studies have pointed to the cultural and social status of these markets (Masaru \& Badenoch, 2013). So far, a few studies have been conducted on the ways that can enhance the social role of these markets which increase social interactions among citizens. Also, the proposed solutions have been generic without taking into account the potentials available at the venue for these markets (Aram,

\footnotetext{
* Corresponding author.

E-mail addresses: ebrahim.solgi@griffithuni.edu.au, solgi_e@yahoo.com (E. Solgi).
} 
2015).

Since public space in cities is a context in which human activities such as the social, economic, recreational, take place (Koohsari, Kaczynski, Giles-Corti, \& Karakiewicz, 2013; Madanipour, 2001), the higher the quality of urban space, the higher the number of activities that take place (Ward Thompson, 2013). As an element of quality, green space, whether independent as a public space or combined with public spaces, has always had a special role in ensuring the presence of residents and enhancing social interactions (Kaczynski \& Henderson, 2007; Comstock et al., 2010; Kemperman \& Timmermans, 2014; Kaźmierczak, 2013). Indeed, green space is a suitable setting for leisure time, relaxation and social interactions (Gehl, 1987; Bonaiuto, Aiello, Perugini, Bonnes, \& Ercolani, 1999; Byrne, 2012), improving physical and mental health in conjunction with other urban spaces (Wolch, Byrne, \& Newell, 2014; Barton \& Pretty, 2010; De Vries, 2010; BedimoRung, Mowen, \& Cohen, 2005). It is also imperative to note that the development of green space and its relationship with other urban spaces is one of the criteria for urban environment planning, which is among the most important duties of urban institutions (Wright, 2000).

\section{The theoretical context}

There are two dominant perspectives in psychological studies related to the impact of natural and green space. The first Psych Evolutionary Theory (PET) proposes the role of natural and green space in stress relief. Evidently, increased communication with natural space has a negative relationship with stress and is associated positively with positive affect (Herzog \& Strevey, 2008; Ulrich, 1983; Ulrich et al., 1991). The second approach, based on the studies of Kaplan and Kaplan, (1989), is known as Attention Restoration Theory (ART), which stresses the effect of green space and natural elements on positive social relationships and personal growth (Herzog \& Strevey, 2008). In this research, attention is paid to the role of green space in increasing social interactions, and in this section the studies that have been conducted in this field are analyzed.

Behavioral observations have shown that social interactions in green spaces are twice as frequent as the interactions in dry and vegetation-free spaces (Sullivan, Kuo, \& DePooter, 2004). Green urban spaces influence the behavior of citizens, and it is feasible that through proper and purposeful planning, and by the suitable placement of green spaces in combination with other urban spaces, the ethical promotion and social grounds required for establishing civic interactions are met (Choy, 1986). According to studies carried out in Greater Manchester in the UK, local parks in inner-city neighborhoods could provide appropriate opportunities for social ties, and thus play a key role in the development of new social interactions and in strengthening existing contacts (Kaźmierczak, 2013). Moreover, a study conducted by Comstock et al. (2010) in Denver, Colorado, USA, showed that some activities, such as participation in recreational gardening (in open green spaces), provide conditions for residents to have social interactions. Another study conducted in Ireland found that in neighborhoods where walkable spaces together with local parks are provided, residents have greater familiarity and trust regarding each other (Leyden, 2003) In general, A green space can be objectively perceived in urban planning terms as containing greenery and a sense of liveliness, and increasing social interaction among residents is one of its paramount characteristics (Kemperman \& Timmermans, 2014). In addition to surveys that generally address the impact of green space, there is also research that focuses on other aspects of green space in increasing social interaction. The majority of these studies have emphasized different age and gender groups, various ethnic and social groups, as well as effective factors in promoting the role of green spaces with regard to increasing interactions. In addition to studies that generally address the impact of green space on social interactions, there are other studies that address other aspects of this topic, which can be divided into three main categories: 1 . The impact of green space on the social interactions of different age groups and gender, 2. The impact of green space on the social interactions of different ethnic groups and socioeconomic elements, 3. Effective factors in promoting the role of green spaces toward increasing interactions.

There are a number of studies related to the impacts of green spaces on social interactions which have specifically investigated these impacts on different age groups and gender groups. A study carried out by Seeland, Duebendorfer, and Hansmann (2008) in Switzerland on the parks and forests of Zurich showed that teenagers mostly set their appointments with their peers in parks and green spaces that are readily available. Another investigation in Switzerland of children aged 10 revealed that interactions and meetings with peers near a green space are considerable, and the most common reason for this is that the green space gives children a space which is entertaining and safe (Jansson, Sundevall, \& Wales, 2016). Even at the scale of small spaces within urban neighborhoods, green spaces, as common space, can be a medium for the gathering and communication of neighbors, particularly for women and the elderly dwellers in the neighborhoods (Kweon, Sullivan, \& Wiley, 1998).

Studies have also been conducted on the role of green spaces on various socioeconomic and ethnic groups. Research conducted in the Netherlands revealed that green areas including urban parks have significant impact on stimulating social cohesion and can provide a vital locality where everyday experiences are shared and negotiated with a variety of people, especially different ethnic groups (Peters, Elands, \& Buijs, 2010). The Latin American study carried out by Krellenberg, Welz, and Reyes-päcke (2014) within the metropolitan area of Santiago in Chile, showed that in low-status neighborhoods where the construction of socioeconomic strata was analyzed, the green spaces, given the potential for spatial interaction play a very important role in establishing social interactions between different socioeconomic status groups.

In another study on this issue in another part of Santiago by de la Barrera, Reyes-Paecke, Harris, Bascuñán, and Farías (2016), it is demonstrated that in three socioeconomically differentiated neighborhoods that residents' perception of social and environmental interactions was widely influenced by green space, and it is more frequent in lower-income neighborhoods where green space is considered an important indicator of quality of life.

What has recently been noted in studies in this area is the feature of green spaces, including its location in the city, which increases its social role. A study in the city of Putrajaya, Malaysia, by (Moulay, Ujang, \& Said, 2017), showed that the legibility of green spaces includes elements such as: 1) distinct structures 2) lack of visual obstacles and 3) accessibility, which is an important feature that increases the attendance of people in the green space and, as a result, raises social interactions. Also, a study in the Shanghai city of China showed that access and quality of urban public green spaces are effective factors in strengthening the social factor in urban neighborhoods, especially in regard to poor neighborhoods (Li \& Liu, 2016). Another study conducted in Phnom Penh, Cambodia, found that the safety factor in the green spaces raises behavioral intention to increase the presence of green spaces and is the basis for social encounters in the youth age group (Yen et al., 2017).

Despite the studies that have been carried out, there is still debate over the general characteristics of green spaces (accessibility, legibility and safety) and their role in social activities, and there is no discussion in detail about the spaces and elements in these green spaces. Also, the social role of green spaces along with other economic, cultural and social spaces, due to the potential of these spaces, needs to be further explored.

Considering the role that green spaces plays in promoting quality and increasing social interactions, the placement of these spaces within the periodic markets can strengthen the social role of markets. Therefore, given the research gap in this area, there is a need for an accurate study which compares periodic markets with and without 
green space. In so doing, the effectiveness of green space as a solution to increase the social role of these types of markets can be evaluated.

The main purpose of the research is to demonstrate the effects of green spaces on social interactions, with focus on places where the periodic markets are held. Furthermore, the details of the quality of green spaces connected with the presence of these markets that reveals which elements can affect the quality of green space will also be investigated.

\section{Methodology}

\subsection{Study site}

Periodic markets, which are called weekday markets, for example, Saturday Market, Monday Market, and so forth, have traditionally been held in various urban spaces in Iran including Hamadan City, situated in the west of the country. Hamadan is reputed as the first Iranian capital and one of the oldest cities in the world (Fazlikhani, Goudarzi, \& Solgi, 2017).

Given that some of the open spaces in Hamadan are in the form of green spaces and so-called "Chaman" (which in Persian means a green prairie) over time and along with urban development and the falling off of the aforesaid spaces, these markets were located close to prairies and urban gardens under municipal ownership, these sites were turned into parks where the green space was thence preserved. In Hamadan, there were two public gardens, Honarestan and Sheshsad Dastgah which exist today as parks and green spaces; used to be held primarily near these gardens. A part of the abovementioned gardens near the Honarestan market is still under private ownership (Aram, 2015).

Hamadan sees nine street markets a week in its different areas, out of which in order to obtain more accurate results, these neighborhoods were selected for the study, corresponding with each other in terms of economic and socio-cultural structures. In fact, in this research, the economic indicator is based on the average income of residents and the average price of housing per square meter, according to Iran's population and housing census in 2011(Iranian Center for Statistics, 2011), and equating the Iranian currency value to the US dollar. The social indicator is also based on prevailing occupations of the local community. In the group of "neighborhoods with green space and street market" in Honarestan, Sheshsad Dastgah, Farhangian, the average monthly income of residents is more than $\$ 2,500$, less than $\$ 1,500$, and less than $\$ 900$, and the average housing price per square meter is $\$ 15,000, \$ 1,000$, and $\$ 700$, respectively. Beyond the prevalence of selfemployment, employees of the three neighborhoods consist mainly of managers, engineers, and teachers. Therefore, it can be said that the neighborhoods of Honarestan, Sheshsad Dastgah, and Farhangian Town are categorized as very good, good, and average neighborhoods in Hamadan, in terms of economic and socio-cultural structures. Further, in the group of "green space-free neighborhoods with street market", Motekhasesin, Resalat, and Shahid Madani Town ware are categorized as very good, good, and average neighborhoods in Hamadan (Fig. 1). In the neighborhood of Motekhasesin, the average income is more than $\$ 3,000$, and one square meter housing price is more than $\$ 2500$; and the main occupations of most residents are university staff and doctors. Meanwhile, the average income of the neighborhood of Resalat is less than $\$ 1,200$, and one square meter housing price is less than $\$ 900$ and the majority of its residents are employees and retailers. The price of land and income in Shahid Madani Town is similar to Farhangian Town, and most of its residents are army personnel and teachers.

In the terms of statistical population, the first group comprised of people residing in the three neighborhoods of Honarestan, Sheshsad Dastgah and Farhangian Town, where Thursday, Tuesday, and Saturday markets are held, respectively. Adjacent to these markets, a pleasant green space such as a park is available. The second group included those residing in the neighborhoods of Motakhasesin, Shahid Madani Town and Resalat, where Sunday, Wednesday and Tuesday markets are held, respectively. It should be noted that periodic markets in Hamedan are established by a number of vendors, who are licensed by the Hamedan municipality, and circulated within in the neighborhoods throughout the week. Thus, the products offered and the size of the markets are approximately the same. The difference between the two groups is that no green space is available close to the periodic markets of the second group, and if present, it is very limited and unfav210.orable.

\subsection{Data analysis}

For the present research, a descriptive exploratory research method was used to examine the conditions and situation of periodic markets in Hamedan, especially from a social and cultural perspective. The sample size characteristics: The number of statistical population is 180 questionnaires $(\mathrm{N}=180)$ and according to the number of neighborhoods (up to 6) an attempt was made to select the interviewees regardless of the appropriateness of the statistical population of the neighborhoods.

The interview and distribution of questionnaires were conducted randomly among residents who were present in houses or in the neighborhood. The data was collected in each neighborhood for a more detailed survey on a day other than the day of the market and during two weeks in October 2016. Furthermore, to obtain valid data, data was collected at different times. In the first week, from 9 to 11 a.m. on Saturday to Thursday (October 8 to 13), the questionnaires from Shahid Madani Town, Honarestan, Motekhasesin, Farhangian Town, Resalat, and Sheshsad Dastgah were collected, consecutively. In the second week, from about 3 to 5 p.m. on Saturday to Thursday (October 15 to 20), the questionnaires were obtained, consecutively from the neighborhoods of Honarestan, Shahid Madani Town, Farhangian Town, Motekhasesin, Sheshsad Dastgah and Resalt.

The mean of the social data was called the variable of social interactions and the extent of attendance of residents in the market was considered to be the attendance variable. Another variable investigated at the end of the research was the quality of green space in local markets. Based on the questions related to the section related to green space quality in the questionnaire, indices such as flooring, accessibility, and desirability of the green space were examined.

Following data coding and categorization of information, data analysis was performed using SPSS software, followed by the preparation of tables and diagrams with Excel. To analyze the information, two statistical methods of descriptive and inferential statistics were used. Descriptive statistics including mean, mode and median were used in the methods and the relevant techniques. Inferential statistics were used in the methods of parametric tests including a KolmogorovSmirnov test and a p-value of variable normality test.

The questions in the questionnaire were examined in terms of reliability and validity, but, for the sake of brevity, not detailed. To analyze the variables of the research, the Cronbach Alpha method was used. According to this method, providing that the coefficient of the data is higher than 0.7 , the questionnaire has a favorable reliability, and consequently, the internal consistency of the questionnaire's questions can be reliable. The Cronbach Alpha coefficient of all questions was 0.741 , and the coefficient related to the questions on the variables of this research (consisting of 18 questions) was 0.778 . Most of the coefficients obtained through the Cronbach Alpha method were greater than 0.7 , confirming the validity of the questions.

The principal variable in this research is the attendance of residents in periodic markets and the role of green spaces in raising social interactions among people. Accordingly, based on the nature of markets and their economic features, the attendance of residents was found to be mainly attributable to meeting their daily needs. Attendance of residents in periodic markets with and without green spaces, and the extent and number of visits to these markets during one month, were considered as the most important indexes (Table 1 ). 


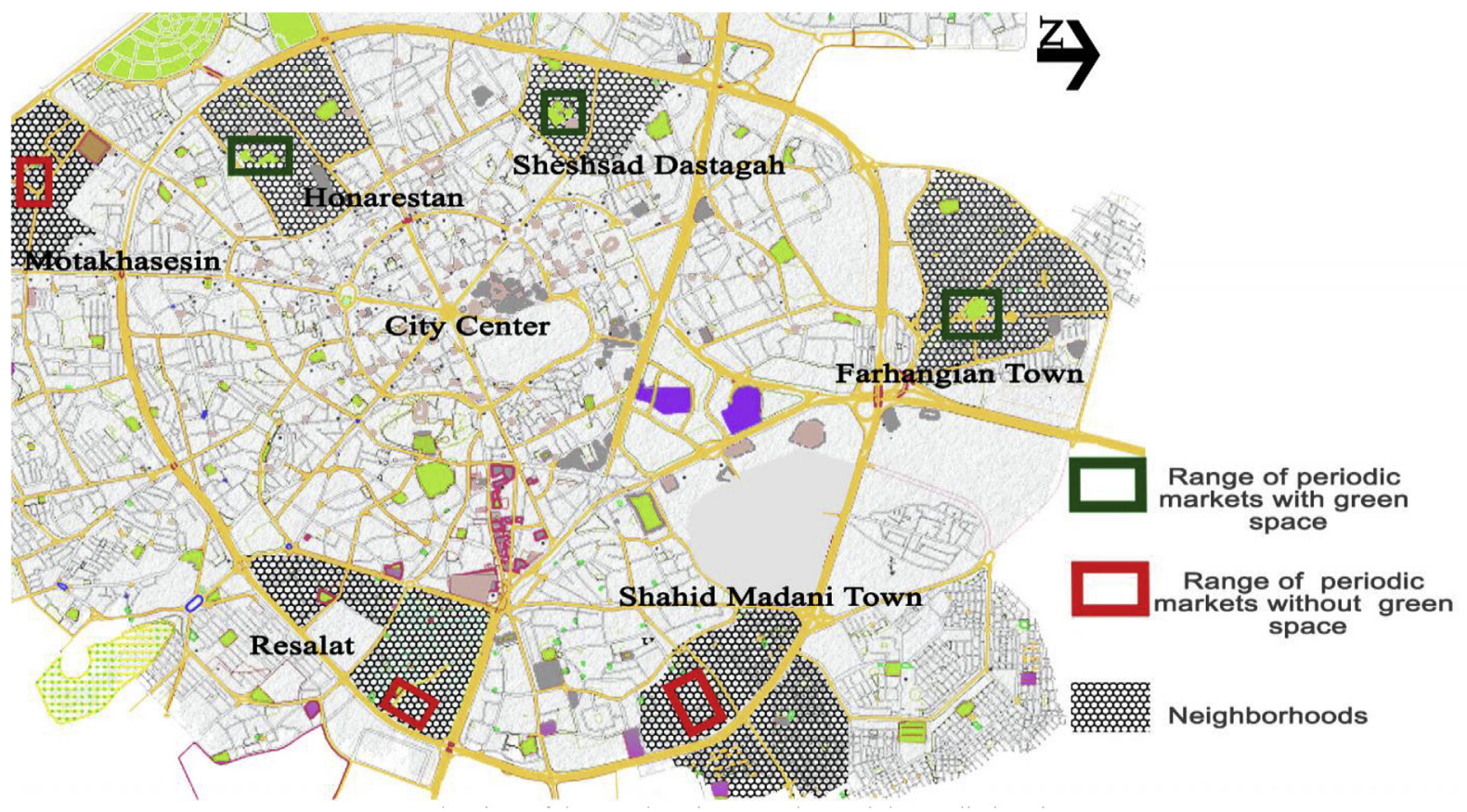

Fig. 1. The sites of day markets in Hamadan and the studied regions.

\section{Results}

This research attempts to find the relationship between the presence of green space close to these periodic markets and the visits and attendance of residents, as well as the subsequent augmentation of social interactions in neighborhoods of periodic markets. In this research, the questions in the social section of the questionnaire that consider the variable of social interactions referred to the degree of social interactions, the sense of belonging in residents to the neighborhood (sense of responsibility and liking), familiarity of neighbors, and the degree of cooperation.

\subsection{The extent of the effect on social interactions of green space close to periodic markets}

First, through descriptive statistical methods, the diagram of the mean of social variables was obtained from the related questions in the questionnaire, and the data was developed and analyzed for the neighborhoods having periodic markets with and without green space. The conclusion from the diagram of the mean of the variables of attendance and social interactions is that in periodic markets with green space of 3.04 and 3.34 respectively, not only is the mean attendance of people greater, but also the social interactions among these residents are greater than those in markets lacking green space, with 2.09 and 2.70 respectively (Fig. 2).

In another analysis, the problem was dealt with to greater extent, and the mean of the variables of attendance and social interactions was investigated in individual neighborhoods. The obtained results indicated that in three neighborhoods, Farhangian Town, Honarestan and Sheshsad Dastgah, where periodic markets are taking place close to green spaces, the mean of the variables of attendance of $2.43,3.73$ and 2.96 respectively in the market, as well as social interactions, respectively of 3.16, 3.58 and 3.28, was independently greater than each of the three neighborhoods lacking green space (Fig. 3).

Table 2 summarizes the score of the investigated variables across the neighborhoods having periodic markets with green space. As is illustrated, in the Honarestan neighborhood, the score of extent of attendance (with a mean of 3.73 and standard deviation of 0.16 ), and the mean of the score of social interactions (with a mean of 3.58 and standard deviation of 0.13 ) are greater than the mean of these two dimensions in the Farhangian and Sheshsad Dastgah neighborhoods.

Table 3 summarizes the scores of the investigated variables across the neighborhoods lacking periodic markets with green space. As shown, in the Resalat neighborhood, the score of the extent of attendance (with a mean of 2.16 and standard deviation of 0.20 ) is greater than the mean of the extent of attendance in the Shahid Madani Town and Motakhasesin neighborhoods. The mean score of social interactions (with a mean of 3.03 and standard deviation of 0.20) in the Motakhasesin neighborhood is higher than the mean of these two variables in the Shahid Madani Town and Resalat neighborhoods.

\subsection{The extent of social interactions across the neighborhoods having periodic markets with and without green space}

To examine the difference between the extent of social interactions across the neighborhoods enjoying periodic markets with and without green space and considering the normality of the social variable across the two groups, a $t$-test was used. Table 4 illustrates that based on pvalue $=0.000$, the difference between the social interactions in the two neighborhood groups with and without green space was statistically significant.

\subsection{The relationship between the extent of attendance and visit to periodic markets with social interactions of residents}

Since the extent of visit and attendance is a qualitative variable at five levels of very low, low, medium, high and very high, and considering the fact that the variable of social interactions follows normal distribution, the analysis of variance test was used so as to investigate the relationship between the extent of attendance and social interactions.

In Table 5 , as p-value $=0.560$ (larger than the significance alpha level of 0.05), then the null hypothesis of the significance of the relationship between the extent of attendance with social interactions in neighborhoods having periodic markets without green space can be neglected. Thus, it can be stated that there is a minor relationship between these two variables in this group of neighborhoods. As pvalue $=0.001$ is lower than the significance alpha level of 0.05 , the 
Table 1

Data of the research's variables.

\begin{tabular}{|c|c|c|c|c|c|c|c|}
\hline \multirow[t]{3}{*}{ Variable } & \multirow[t]{3}{*}{ Categories } & \multicolumn{6}{|l|}{$\%$} \\
\hline & & \multicolumn{3}{|c|}{$\begin{array}{l}\text { Neighborhoods having periodic markets without green } \\
\text { space }\end{array}$} & \multicolumn{3}{|c|}{ Neighborhoods having periodic markets with green space } \\
\hline & & Shahid Madani & Motakhasesin & Resalat & Sheshsad Dastgah & Honarestan & Farhangian Town \\
\hline \multirow[t]{5}{*}{ Age } & $13-18$ & 6.7 & 0.0 & 3.3 & 3.3 & 3.3 & 0.0 \\
\hline & $19-25$ & 26.7 & 13.3 & 53.3 & 16.7 & 23.3 & 13.3 \\
\hline & $26-40$ & 30.0 & 53.3 & 26.7 & 36.7 & 33.3 & 53.3 \\
\hline & $41-60$ & 26.7 & 30.0 & 16.7 & 36.7 & 23.3 & 33.3 \\
\hline & $61-75$ & 10.0 & 3.3 & 0.0 & 6.7 & 16.7 & 0.0 \\
\hline \multirow[t]{2}{*}{ Gender } & Men & 53.3 & 66.7 & 63.3 & 46.7 & 43.3 & 43.3 \\
\hline & Women & 46.7 & 33.3 & 36.7 & 53.3 & 56.7 & 56.7 \\
\hline \multicolumn{8}{|l|}{ Attendance in the periodic markets } \\
\hline \multirow{5}{*}{$\begin{array}{l}\text { - Number of visits during one } \\
\text { month }\end{array}$} & Never or Once & 43.3 & 30.0 & 36.7 & 30.0 & 3.3 & 6.7 \\
\hline & twice & 20.0 & 46.7 & 26.7 & 20.0 & 3.3 & 26.7 \\
\hline & Three times & 23.3 & 13.3 & 20.0 & 36.7 & 26.7 & 40.0 \\
\hline & Four times & 10.0 & 10.0 & 16.7 & 3.3 & 50.0 & 16.7 \\
\hline & Five times or more & 3.3 & 0.0 & 0.0 & 10.0 & 16.7 & 10.0 \\
\hline \multirow[t]{5}{*}{ - A variety of different strata } & Very low & 6.7 & 13.3 & 6.7 & 0.0 & 13.3 & 0.0 \\
\hline & Low & 20.0 & 36.7 & 16.7 & 13.3 & 13.3 & 20.0 \\
\hline & Medium & 20.0 & 26.7 & 46.7 & 30.0 & 16.7 & 26.7 \\
\hline & High & 43.3 & 10.0 & 10.0 & 26.7 & 23.3 & 43.3 \\
\hline & Very high & 10.0 & 13.3 & 20.0 & 30.0 & 33.3 & 10.0 \\
\hline \multicolumn{8}{|l|}{ Social contacts } \\
\hline \multirow{5}{*}{$\begin{array}{l}\text { - Social interactions with } \\
\text { neighbors }\end{array}$} & Very low & 13.3 & 3.3 & 10.0 & 3.3 & 0.0 & 3.3 \\
\hline & Low & 10.0 & 16.7 & 30.0 & 20.0 & 13.3 & 20.0 \\
\hline & Medium & 26.7 & 40.0 & 23.3 & 30.0 & 26.7 & 36.7 \\
\hline & High & 33.3 & 23.3 & 26.7 & 43.3 & 33.3 & 40.0 \\
\hline & Very high & 16.7 & 16.7 & 10.0 & 3.3 & 26.7 & 0.0 \\
\hline \multirow[t]{5}{*}{ - Opportunity of communicating } & Bad & 20.0 & 10.0 & 13.3 & 3.3 & 3.3 & 3.3 \\
\hline & $\begin{array}{l}\text { Sometimes good/ } \\
\text { bad }\end{array}$ & 23.3 & 50.0 & 43.3 & 43.3 & 16.7 & 53.3 \\
\hline & Moderate & 13.3 & 16.7 & 23.3 & 36.7 & 20.0 & 26.7 \\
\hline & Good & 23.3 & 20.0 & 13.3 & 10.0 & 33.3 & 16.7 \\
\hline & Very good & 20.0 & 3.3 & 6.7 & 6.7 & 26.7 & 0.0 \\
\hline \multirow{5}{*}{$\begin{array}{l}\text { - Sense of belonging and } \\
\text { attachment }\end{array}$} & Very low & 16.7 & 13.3 & 13.3 & 3.3 & 0.0 & 3.3 \\
\hline & Low & 46.7 & 26.7 & 20.0 & 10.0 & 23.3 & 20.0 \\
\hline & Medium & 13.3 & 23.3 & 50.0 & 46.7 & 36.7 & 30.0 \\
\hline & High & 20.0 & 30.0 & 13.3 & 36.7 & 30.0 & 33.3 \\
\hline & Very high & 3.3 & 6.7 & 3.3 & 3.3 & 10.0 & 13.3 \\
\hline - Friendship and Cooperation & Bad & 43.3 & 13.3 & 16.7 & 13.3 & 3.3 & 10.0 \\
\hline & $\begin{array}{l}\text { Sometimes good/ } \\
\text { bad }\end{array}$ & 26.7 & 10.0 & 16.7 & 10.0 & 3.3 & 16.7 \\
\hline & Moderate & 20.0 & 36.7 & 30.0 & 40.0 & 20.0 & 30.0 \\
\hline & Good & 6.7 & 26.7 & 26.7 & 30.0 & 46.7 & 26.7 \\
\hline & Very good & 3.3 & 13.3 & 10.0 & 6.7 & 26.7 & 16.7 \\
\hline Quality of green space & & & & & & & \\
\hline - Number of urban furniture & Very Bad & & & & 23.3 & 20.0 & 20.0 \\
\hline & Bad & & & & 33.3 & 30.0 & 33.3 \\
\hline & Moderate & & & & 16.7 & 10.0 & 46.7 \\
\hline & Good & & & & 23.3 & 20.0 & 0.0 \\
\hline & Very good & & & & 3.3 & 20.0 & 0.0 \\
\hline - Beauty of urban elements & Very low & & & & 33.3 & 36.7 & 53.3 \\
\hline & Low & & & & 40.0 & 23.3 & 33.3 \\
\hline & Medium & & & & 10.0 & 13.3 & 13.3 \\
\hline & High & & & & 3.3 & 13.3 & 0.0 \\
\hline & Very high & & & & 13.3 & 13.3 & 0.0 \\
\hline - Quality of flooring & Very Bad & & & & 10.0 & 10.0 & 6.7 \\
\hline & Bad & & & & 26.7 & 33.3 & 20.0 \\
\hline & Moderate & & & & 36.7 & 36.7 & 53.3 \\
\hline & Good & & & & 16.7 & 6.7 & 3.3 \\
\hline & Very good & & & & 10.0 & 13.3 & 16.7 \\
\hline - Vegetation and greenness & Very Bad & & & & 3.3 & 6.7 & 26.7 \\
\hline & $\mathrm{Bad}$ & & & & 23.3 & 33.3 & 20.0 \\
\hline & Moderate & & & & 53.3 & 20.0 & 43.3 \\
\hline & Good & & & & 20.0 & 16.7 & 10.0 \\
\hline & Very good & & & & 0.0 & 23.3 & 0.0 \\
\hline
\end{tabular}

null hypothesis of the significance of the relationship between the extent of attendance with social interactions in the neighborhoods having periodic markets with green space was accepted. It can thus be said that the relationship between the extents of attendance with social interactions in this group of neighborhoods is statistically significant.
4.4. The effect of the quality of green space close to periodic markets on the attendance of the neighborhood residents

In the questionnaire offered to the residents, some questions were formulated for the physical conditions section which dealt with the 


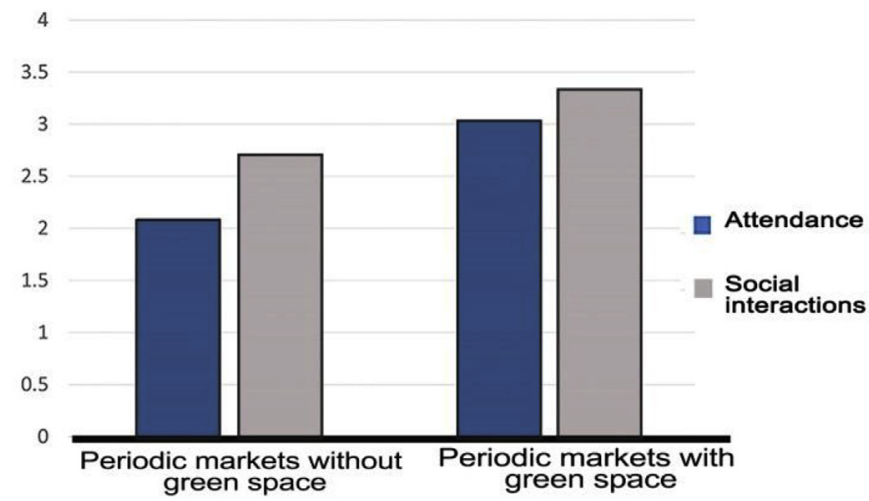

Fig. 2. Mean of the research variables in periodic markets with and without green space.

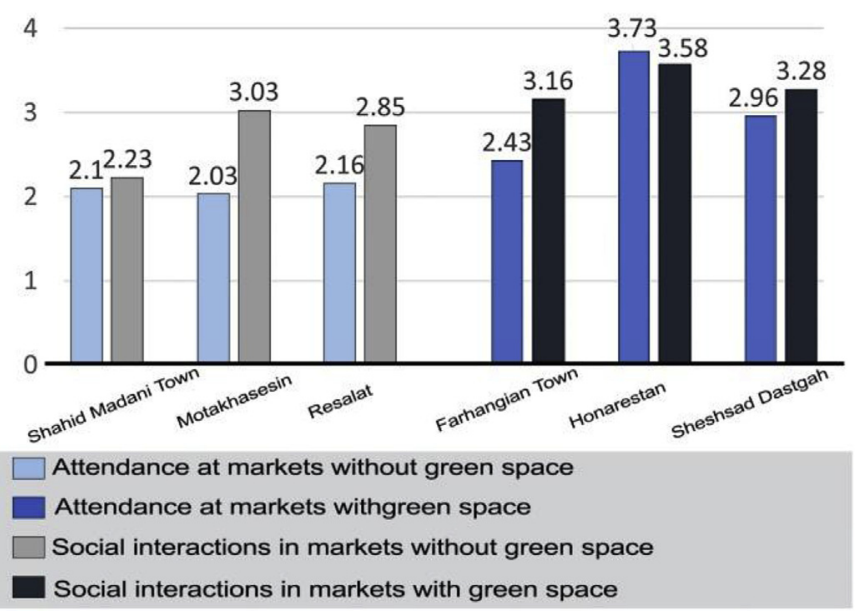

Fig. 3. Mean of the variables of people's attendance and social interactions were investigated in individual neighborhoods.

Table 2

Summarizes the score of the investigated variables across the neighborhoods having periodic markets with green space.

\begin{tabular}{lllllll}
\hline Variable & \multicolumn{2}{l}{ Farhangian Town } & \multicolumn{2}{l}{ Honarestan } & \multicolumn{2}{l}{ Sheshsad Dastgah } \\
\cline { 2 - 7 } & Mean & $\begin{array}{l}\text { Standard } \\
\text { Deviation }\end{array}$ & Mean & $\begin{array}{l}\text { Standard } \\
\text { Deviation }\end{array}$ & Mean & $\begin{array}{l}\text { Standard } \\
\text { Deviation }\end{array}$ \\
\hline Attendance & 2.43 & 0.22 & 3.73 & 0.16 & 2.96 & 0.19 \\
Social interactions & 3.16 & 0.13 & 3.58 & 0.13 & 3.28 & 0.18 \\
\hline
\end{tabular}

Table 3

Summarizes the score of the investigated variables across the neighborhoods lacking periodic markets without green space.

\begin{tabular}{lllllll}
\hline Variable & \multicolumn{2}{l}{$\begin{array}{l}\text { Shahid Madani } \\
\text { Town }\end{array}$} & Motakhasesin & \multicolumn{2}{l}{ Resalat } \\
\cline { 2 - 7 } & Mean & $\begin{array}{l}\text { Standard } \\
\text { Deviation }\end{array}$ & Mean & $\begin{array}{l}\text { Standard } \\
\text { Deviation }\end{array}$ & Mean & $\begin{array}{l}\text { Standard } \\
\text { Deviation }\end{array}$ \\
\hline Attendance & 2.10 & 0.21 & 2.03 & 0.16 & 2.16 & 0.20 \\
Social interactions & 2.23 & 0.17 & 3.03 & 0.20 & 2.85 & 0.19 \\
\hline
\end{tabular}

quality of green spaces in terms of vegetation and greenness, the presence of urban furniture, the beauty of furniture, urban elements, and flooring. Finally, it was found that, according to the criteria mentioned (Table 6), the desirability of green space in the periodic market of the Honarestan neighborhood with mean 2.82 is greater than that in
Farhangian and Seshsad Dastgah neighborhoods with 2.63 and 2.31 respectively, and thus has a more desirable status (Fig. 4).

Analysis of the data of the criteria of green space quality in Table 7 revealed that the mean of the data related to existence of urban furniture, the beauty of urban elements and the vegetation of the Honarestan neighborhood with the respective values of $2.9,2.43$ and 3.16 , is greater than that of the other two neighborhoods. Moreover, based on the standard deviation of the data, the beauty of urban elements with the greatest standard deviation value of 0.35 had the highest significance in the high mean of the green space quality of the Honarestan neighborhood (Fig. 5). The green space and availability of urban furniture with the standard deviation values of 0.33 and 0.26 respectively were next in significance. The desirability of flooring, based on the mean value of 2.8 and standard deviation of 0.09 , has the lowest degree of influence among the qualitative enhancements of the Thursday market in the Honarestan neighborhood.

\section{Discussion}

The use of other space potential along with the green spaces and the interrelationship of these spaces have been one of the socioeconomic spaces of interest to scholars in the field of urban studies (Brink et al., 2016; Raymond et al., 2017; Wan \& Shen, 2015). Also, a recent study conducted by Faivre, Fritz, Freitas, and Boissezon (2017) found that the use of innovative solutions and attention to the features of green spaces along with other spaces as a socioeconomic environment has been a very important issue in developing future urban planning.

The findings of the research indicated that regions where periodic markets are held in connection with green spaces unlike regions lacking green spaces, are of great importance in developing more socialization and enhancing social interactions among their residents. This is a basis for the forming of acquaintance among neighbors with each other since markets are an event which local people attend.

\subsection{Social interactions in periodic markets}

"Markets as Sites for Social Interaction" (Watson and Studdert, 2006) is a project aimed at determining the significance of markets as social spaces in cities and towns in England. In recent years, in spite of some local disparities, the reduction in the number of local retail markets in England has been greater than that of the past 20 years. According to the findings of this research, the main reasons for this phenomenon are the lack of sufficient support by the relevant organizations, and a reduction in the quality of services in these markets. Notably, with the aim of considering the role of markets as social spaces, this report specifically investigated the significance of markets for different groups in society, as well as forms of interaction of policies enacted in market venues.

In the US, weekly and daily markets are known as farmer markets. They are held in the majority of urban areas, such as downtown New York in Manhattan Union Square, playing a key role in the US in developing the attendance of people and social interactions in urban spaces. In research titled "The Value of Farmer Markets to New York Communities (2006)", farmer markets of 64 towns in New York State were investigated. According to this research, a total number of 235 farmer markets existed in New York State in 2000. In 2006, this figure had increased to 350 , showing a $49 \%$ growth. Based on this research, farmer markets promote the social, physical and health conditions of a society. Farmer markets are a sustainable site for holding seasonal or weekly events, in which music programs or performance and spatial festivals are held for children. Indeed, in addition to presenting a site for buying and selling goods, these markets are a site for entertainment and social communication. In this era of diminished social contact, the presence of these markets represents a trend towards reinforcing the bonds between people in a neighborhood. Consequently, for those who might have little opportunity of developing a positive bond and 
Table 4

T-test for examining the difference between the extent of social interactions across the two neighborhood groups with and without green space.

\begin{tabular}{|c|c|c|c|c|c|c|}
\hline Variable & & Mean & Standard Deviation & mean difference & Statistic value & $\mathrm{p}$-value \\
\hline \multirow[t]{2}{*}{ Social interactions } & Neighborhoods having periodic markets with green space & 2.70 & 0.11 & -0.64 & -4.40 & 0.000 \\
\hline & Neighborhoods having periodic markets without green space & 3.34 & 0.08 & & & \\
\hline
\end{tabular}

Table 5

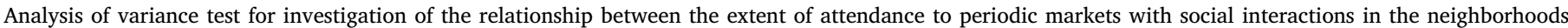
having periodic markets with and without green space.

\begin{tabular}{|c|c|c|c|c|c|c|}
\hline groups & The second regression model & Sum of squares & Degrees of freedom & Mean square & F -statistic & p-value \\
\hline \multirow[t]{3}{*}{ Neighborhoods having periodic markets without green space } & Regression & 3.56 & 4 & 0.89 & 0.751 & 0.560 \\
\hline & Remaining & 100.8 & 85 & 1.18 & & \\
\hline & Total & 104.4 & 89 & & & \\
\hline \multirow[t]{3}{*}{ Neighborhoods having periodic markets with green space } & Regression & 12.9 & 4 & 3.24 & 5.38 & 0.001 \\
\hline & Remaining & 51.3 & 85 & 0.60 & & \\
\hline & Total & 64.3 & 89 & & & \\
\hline
\end{tabular}

Table 6

Summarizes the score quality of green space across the neighborhoods having periodic markets with green space.

\begin{tabular}{lllllll}
\hline variable & \multicolumn{2}{l}{ Farhangian } & \multicolumn{2}{l}{ Honarestan } & \multicolumn{2}{l}{ Sheshsad Dastgah } \\
\cline { 2 - 7 } & Mean & $\begin{array}{l}\text { standard } \\
\text { deviation }\end{array}$ & Mean & $\begin{array}{l}\text { standard } \\
\text { deviation }\end{array}$ & Mean & $\begin{array}{l}\text { standard } \\
\text { deviation }\end{array}$ \\
\hline Desirability & 2.63 & 0.33 & 2.82 & 0.3 & 2.31 & 0.58 \\
\hline
\end{tabular}

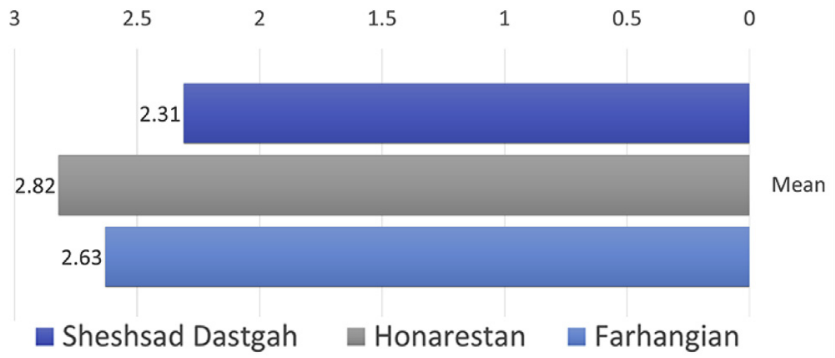

Fig. 4. Mean of quality in green space across the neighborhoods having periodic markets with green space.

Table 7

Summarizes the score criteria of green space quality across the neighborhoods having periodic markets with green space.

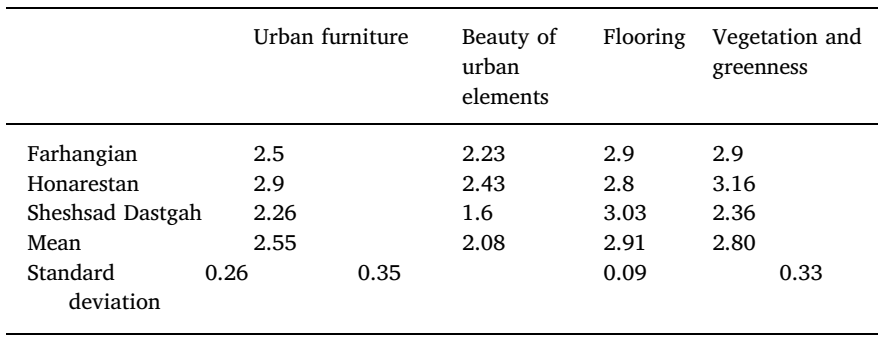

interaction with their neighbors, these markets are a suitable channel.

A comprehensive 2003 research plan titled "Public Markets as a Vehicle for Social Integration and Upward Mobility" (The Ford Foundation, 2003) studied public spaces and periodic markets in the US, and both reviewed the background of studies in this field and depicted a brief profile of the present and upcoming challenges. A part of this research was developed through surveys and interviews with the managers of eight markets as a sample. Finally, in order to prevent

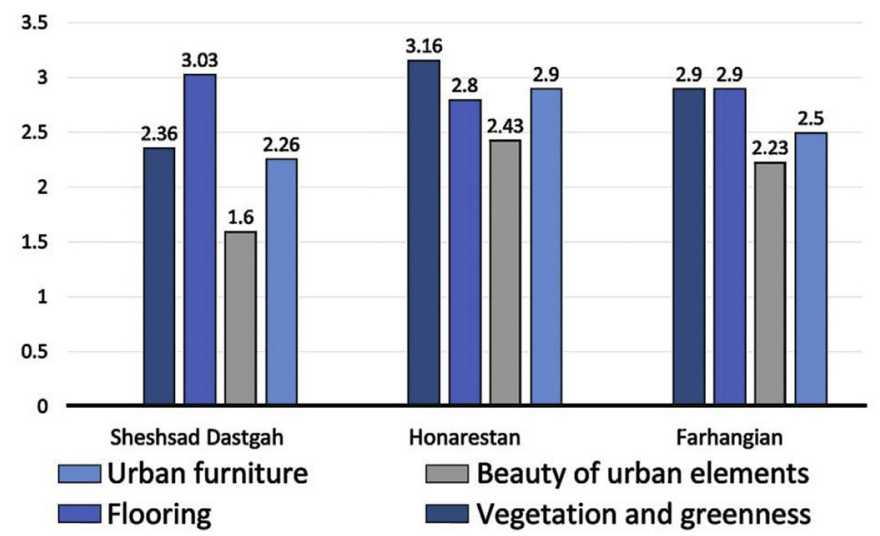

Fig. 5. Mean of criteria of green space quality across the neighborhoods having periodic markets with green space.

urban structures from damage, it was suggested that the following measures, along with their required policies should be taken: 1) identification of opportunities and threats with a view to the future; 2) maintenance of the open spaces as a fundamental necessity of urbanization; and 3) attention to both the economic and social aspects of local and periodic markets.

\subsection{Periodic markets and green spaces}

In the study "public spaces, social interactions and welfare in the east of London (Dines et al., 2006)"; public spaces and social relations, as well as the level of welfare of dwellers in the New Ham neighborhood of Eastern London, were investigated. The east of London includes some deprived regions in England, yet has always had among the most dynamic and active neighborhoods in London, and also social and ethnical diversity. Among the most important spaces considered in a separate chapter in the research is the Queens weekly market, an old market with a straight street form. This market is considered a focus for linking different ethnicities and extensive participation of residents. In this research, its effective role in developing social interactions and communication with various ethnicities was mentioned. Further, the placement of a green space close to this market was also suggested. This study acknowledges that green space can add several special and attractive applications to spaces such as streets or markets, enhancing the environmental quality for the people usage.

Considering domestic experiences, a study entitled "the role of Langrood Market Park in the spatial changes in the city" by Mo'tamedimehr and Moti'doost Koomle (2010), they used for the first 
time the concept of Market Park. They meant a space that had both commercial and recreational functions. In this research while fully describing the procedure of the formation of an adjacent daily market under the title "Friday Market Park", as well as the functions and properties of Langrood Market Park, the main factors affecting the market's economic prosperity were also investigated, rather than social issues and the role of parks in green space in social interactions. The studies that have been done in this section have been case studies, and no comparison has been made with similar green spaces to give more accurate information on how green space in conjunction with periodic markets affects people's presence and social interactions. Given the gap in previous studies, in this research, in addition to comparing the frequency of social interaction in two groups of markets, three markets with green space were separately compared with each other to accurately measure the effective factors.

Green spaces can enhance the social interactions of the inhabitants by strengthening their quality. On the other hand The studies in this section generally point to the positive role of periodic markets in building social relationships, especially in the cities of Iran (Shafiei Sabet \& Azharianfar, 2017), and also show that the polices designed to augment the role of periodic markets in social interactions lack specific approaches. However, the potential of green spaces which are located next to some of these sites represents a valuable socialeconomic space inside the neighborhood centers. In addition to emphasizing the role of green spaces, the existing and effective elements in green spaces, which have increased the impact of green spaces, have been ignored. Therefore, it is important to put a premium on the noteworthiness of having spaces that can play an effective role in socioeconomic spaces. Attention to the elements affecting the quality of green spaces can also be considered as a new strategy for urban planning to increase social interaction in urban neighborhoods.

\section{Conclusion}

Based upon the findings, it can be concluded that in addition to the welcome existence of daily markets in the neighborhoods (attracting residents and large population visits), green space plays a remarkable role in increasing the attendance of residents and social interactions, such that the mean of these two variables in the neighborhoods having green space is greater than those lacking green space. The Thursday market of the Honarestan neighborhood had the highest mean in terms of attendance and social interactions among residents, as well as the Honarestan market in terms of green space quality had the highest mean in comparison with the other two neighborhoods. Thus, it can be stated that increased attendance and social interactions of residents are directly related to the desirability of the green space quality. Based on the results, the factors affecting the qualitative development of the site of these markets, in order of priority are:

\section{Aesthetic allure of urban elements available in the green space \\ 2. Suitability of vegetation \\ 3. Sufficiency of the amount of urban furniture \\ 4: Appropriate flooring}

By developing proper green space or enhancing the quality of available green spaces close to the location of periodic markets, greater attendance of residents in the neighborhoods could be expected. This was followed by greater interactions and familiarity of residents with each other and also with their residential area.

Based on the theoretical concepts and mentioned principles, together with the discussion on urban spaces as areas for people's attendance and social interactions, periodic markets with green space can be considered as regularly held socioeconomic events and as an agent for engaging the population and providing the needs of residents. Furthermore, markets invariably afford human participation and social interactions. Considering today's urban challenges and the decrease in social interactions in urban spaces, the role of these markets can be reinforced as a focus for urban interactions through qualitative factors such as green space.

Finally, it should be taken into consideration that the mere presence of green spaces along with the establishment of periodic markets is not enough; in the design of green space, attention should be paid to elements that increase its quality, and appropriate design solutions. In this research, efforts were made to highlight the importance of green space in increasing the quality of the venue of periodic markets and increasing the attendance of people; however, consideration of how to improve the quality of green elements that enhance the social interaction in periodic markets is also required by future research.

\section{References}

Afsrkshmyry, B. (1993). Weekly rural markets in north of Iran. A Social Sciences, II(3) 192 179.

Aram, F. (2015). Reorganization of local temporary markets considering active presence of neighborhood residents. A case study: Thursday market situated in honerestan neighborhood in hamadan (unpublished master thesis). Tehran, Iran: University of Art.

de la Barrera, F., Reyes-Paecke, S., Harris, J., Bascuñán, D., \& Farías, J. M. (2016). People's perception influences on the use of green spaces in socio-economically differentiated neighborhoods. Urban Forestry and Urban Greening, 20, 254-264. https:// doi.org/10.1016/j.ufug.2016.09.007.

Barton, J., \& Pretty, J. (2010). What is the best dose of nature and green exercise for improving mental health- A multi-study analysis. Environmental Science and Technology, 44(10), 3947-3955. https://doi.org/10.1021/es903183r.

Bedimo-Rung, A. L., Mowen, A. J., \& Cohen, D. A. (2005). The significance of parks to physical activity and public health: A conceptual model. American Journal of Preventive Medicine, 28, 159-168.

Bonaiuto, M., Aiello, A., Perugini, M., Bonnes, M., \& Ercolani, A. P. (1999). Multidimensional perception of residential environment quality and neighborhood attachment in the urban environment. Journal of Environmental Psychology, 19(4), 331-352. https://doi.org/10.1006/jevp.1999.0138.

Brink, E., Aalders, T., Ádám, D., Feller, R., Henselek, Y., Hoffmann, A., \& Wamsler, C. (2016). Cascades of green: A review of ecosystem-based adaptation in urban areas. Global Environmental Change, 36, 111-123. https://doi.org/10.1016/j.gloenvcha. 2015.11.003.

Byrne, J. (2012). When green is White: The cultural politics of race, nature and social exclusion in a Los Angeles urban national park. Geoforum, 43(3), 595-611. https:// doi.org/10.1016/j.geoforum.2011.10.002.

Carr, S., Francis, M., Rivlin, L. G., \& Stone, A. M. (1992). Public space, vol. 40, Cambridge University Press Cambridge University Press400. https://doi.org/10.1007/s11007. 006-9038-x.

Choy, F. (1986). Urbanism, utopia and reality: An anthology, paris, seuil, coll. "Points".

Comstock, N., Miriam Dickinson, L., Marshall, J. A., Soobader, M. J., Turbin, M. S., Buchenau, M. et al. Litt, J. S. (2010). Neighborhood attachment and its correlates: Exploring neighborhood conditions, collective efficacy, and gardening. Journal of Environmental Psychology, 30(4), 435-442. https://doi.org/10.1016/j.jenvp.2010.05. 001.

De Vries, S. (2010). Nearby nature and human health: Looking at mechanisms and their implications. Innovative approaches to researching landscape and health: Open space: People space, Vol. 2, Routledge Taylor \& Francis Group77-96. https://doi.org/10. 4324/9780203853252.

Dines, N., Cattell, V., Gesler, W., \& Curtis, S. (2006). Public spaces, social relations and wellbeing in east London, queen mary. University of London.

Ehinmowo, A. A., \& Ibitoye, A. O. (2010). Periodic market, a common marketing feature in Akoko southwest. Journal of Geography and Regional Planning, 3(12), 361-364.

Faivre, N., Fritz, M., Freitas, T., \& Boissezon, B. De (2017). Nature-Based Solutions in the $\mathrm{EU}$ : Innovating with nature to address social. Economic and Environmental Challenges ts, 159(September), 509-518. https://doi.org/10.1016/j.envres.2017.08.032.

Farmers' Market Federation of New York (2006). The value of farmers' markets to New York's Communities. Funded by project for public spaces with funding from $W$. New York: K. Kellogg Foundation.

Fazlikhani, F., Goudarzi, H., \& Solgi, E. (2017). Numerical analysis of the efficiency of earth to air heat exchange systems in cold and hot-arid climates. Energy Conversion and Management, 148, 78-89. https://doi.org/10.1016/j.enconman.2017.05.069.

Gehl, J. (1987). Life between buildings. Using public space. New York: Van Nostrand Reinhold.

Gehl, J. (2013). Cities for people. Washington DC: Island press.

Herzog, T. R., \& Strevey, S. J. (2008). Contact with nature, sense of humor, and psychological well-being. Environment and Behavior, 40(6), 747-776. https://doi.org/10. 1177/0013916507308524.

Iranian Center for Statistics (2011). Detailed results of the general census of population and housing. Tehran: Publications of the Organization of Planning and Budget of the Islamic Republic of Iran. https://www.amar.org.ir/.

Jansson, M., Sundevall, E., \& Wales, M. (2016). The role of green spaces and their management in a child-friendly urban village. Urban Forestry and Urban Greening, 18, 228-236. https://doi.org/10.1016/j.ufug.2016.06.014.

John, D., \& Chikagbum, C. (2015). Development of rural periodic market Centres: An effective strategy for rural development in rivers state. Nigeria, 9001. 
Kaczynski, A. T., \& Henderson, K. A. (2007). Environmental correlates of physical activity: A review of evidence about parks and recreation. Cooper institute on "parks, recreation, and public health: Collaborative frameworks for promoting physical activity: Vol. 29, (pp. 315-354). . 20064 https://doi.org/10.1080/01490400701394865.

Kaplan, R., \& Kaplan, S. (1989). The experience of nature. A psychological perspective. 360. https://doi.org/10.2307/2011391.

Kaźmierczak, A. (2013). The contribution of local parks to neighbourhood social ties. Landscape and Urban Planning, 109(1), 31-44. https://doi.org/10.1016/j. landurbplan.2012.05.007.

Kemperman, A., \& Timmermans, H. (2014). Green spaces in the direct living environment and social contacts of the aging population. Landscape and Urban Planning, 129, 44-54. https://doi.org/10.1016/j.landurbplan.2014.05.003.

Khosravi, K. (1979). Research on rural society of Iran. Tehran: the message.

Koohsari, M. J., Kaczynski, A. T., Giles-Corti, B., \& Karakiewicz, J. A. (2013). Effects of access to public open spaces on walking: Is proximity enough? Landscape and Urban Planning, 117, 92-99. https://doi.org/10.1016/j.landurbplan.2013.04.020.

Krellenberg, K., Welz, J., \& Reyes-päcke, S. (2014). Urban green areas and their potential for social interaction e A case study of a socio-economically mixed neighbourhood in Santiago de Chile. Habitat International, 44, 11-21. https://doi.org/10.1016/j. habitatint.2014.04.004.

Kweon, B. S., Sullivan, W. C., \& Wiley, A. R. (1998). Green common spaces and the social integration of inner-city older adults. Environment and Behavior, 30(6), 832-858. https://doi.org/10.1177/001391659803000605.

Leyden, K. M. (2003). Social capital and the built environment: The importance of walkable neighbourhoods. American Journal of Public Health, (93), 1546-1551.

Li, H., \& Liu, Y. (2016). Land use policy neighborhood socioeconomic disadvantage and urban public green spaces availability: A localized modeling approach to inform land use policy. Land Use Policy, 57, 470-478. https://doi.org/10.1016/j.landusepol.2016. 06.015 .

Madanipour, A. (2001). Multiple meanings of space and the need for a dynamic perspective. In A. Madanipour, A. Hull, \& P. Healey (Eds.). The Governance of Place. Space and planning processes (pp. 154-168). Ashgate.

Masaru, N., \& Badenoch, N. (2013). Why periodic markets are held: Considering products, people, and place in the yunnan-vietnam border area. South East Asian Studies, 2(1), $171-192$.

Mo'tamedimehr, A., \& Moti'doost Koomle, A. (2010). The role of Langrood Market Park in the spatial changes in the city. The Preparation Geographic Magazine, 11 61-27.

Moulay, A., Ujang, N., \& Said, I. (2017). Legibility of neighborhood parks as a predicator for enhanced social interaction towards social sustainability. JCIT, 61, 58-64. https://doi.org/10.1016/j.cities.2016.11.007.

Peters, K., Elands, B., \& Buijs, A. (2010). Social interactions in urban parks: Stimulating social cohesion? Urban Forestry and Urban Greening, 9(2), 93-100. https://doi.org/10. 1016/j.ufug.2009.11.003.

Raymond, C. M., Frantzeskaki, N., Kabisch, N., Berry, P., Breil, M., Razvan, M., \& Calfapietra, C. (2017). A framework for assessing and implementing the co-bene fi ts of nature-based solutions in urban areas. Environmental Science \& Policy, 77(July),
15-24. https://doi.org/10.1016/j.envsci.2017.07.008

Seeland, K., Duebendorfer, S., \& Hansmann, R. (2008). Making friends in Zurich's urban forests and parks: The role of public green space for social inclusion of youths from different cultures. Forest Policy and Economics, 11, 10-17.

Shafiei Sabet, N., \& Azharianfar, S. (2017). Urban-rural reciprocal interaction potential to develop weekly markets and regional development in Iran. Habitat International, 61, 31-44. https://doi.org/10.1016/j.habitatint.2017.01.003.

Smith, R. H. T. (1979). Periodic market-places and periodic marketing: Review and prospect-I. Progress in Human Geography, 3(4), 471-505. https://doi.org/10.1177/ 030913257900300401.

H.Soltanzadeh 1392 Urban spaces in the historical context of Iran Cultural Research Bureau.

Sommer, R., Herrick, J., \& Sommer, T. R. (1981). The behavioral ecology of supermarkets and farmers' markets. Journal of Environmental Psychology, 1(1), 13-19. https://doi. org/10.1016/S0272-4944(81)80014-X.

Sullivan, W. C., Kuo, F. E., \& DePooter, S. F. (2004). The fruit of urban nature: Vital neighborhood spaces. Environment and Behavior, 36(5), 678-700. https://doi.org/10. 1177/0193841X04264945.

The Ford Foundation (2003). Public markets as a Vehicle for social integration and upward mobility. Public markets as a Vehicle for social integration and upward mobility (pp. 1-56). . New York http://www.pps.org/pdf/Ford_Report.pdf.

Ulrich, R. (1983). Aesthetic and affective response to natural environment. Behavior and the natural environment85-125. https://doi.org/10.1007/978-1-4613-3539-9.

Ulrich, R. S., Simons, R. F., Losito, B. D., Fiorito, E., Miles, M. A., \& Zelson, M. (1991). Stress recovery during exposure to natural and urban environments. Journal of Environmental Psychology, 11(3), 201-230. https://doi.org/10.1016/S0272-4944(05) 80184-7.

Wan, C., \& Shen, G. Q. (2015). Encouraging the use of urban green space: The mediating role of attitude, perceived usefulness and perceived behavioural control. Habitat International, 50, 130-139. https://doi.org/10.1016/j.habitatint.2015.08.010.

Ward Thompson, C. (2013). Activity, exercise and the planning and design of outdoor spaces. Journal of Environmental Psychology. https://doi.org/10.1016/j.jenvp.2013. 01.003.

Watson, S., \& Studdert, D. (2006). Markets as sites for social for social interaction: Spaces of diversity. Joseph Rowntree Foundation1-53. https://www.jrf.org.uk/sites/default/ files/jrf/migrated/files/1940-markets-social-interaction.pdf.

Wolch, J. R., Byrne, J., \& Newell, J. P. (2014). Urban green space, public health, and environmental justice: The challenge of making cities "just green enough. Landscape and Urban Planning, 125, 234-244. https://doi.org/10.1016/j.landurbplan.2014.01. 017.

Wright, F. L. (2000). Broadacre city: A new community plan. In R. LeGates, \& F. Stout (Eds.). The city reader (pp. 325-330). New York, NY: Routledge.

Yen, Y., Wang, Z., Shi, Y., Xu, F., Soeung, B., Tayyab, M., \& Abdalla, S. (2017). The predictors of the behavioral intention to the use of urban green spaces: The perspectives of young residents in Phnom Penh , Cambodia. Habitat International, 64 98-108. https://doi.org/10.1016/j.habitatint.2017.04.009. 